\title{
Erratum to: Laparoscopic resection of paraaortic/paracaval neurogenic tumors: surgical outcomes and technical tips
}

Takashige Abe $^{1} \cdot$ Ataru Sazawa $^{2} \cdot$ Toru Harabayashi $^{3} \cdot$ Yuichiro Oishi $^{1}$. Naoto Miyajima $^{1} \cdot$ Kunihiko Tsuchiya $^{1} \cdot$ Satoru Maruyama $^{1} \cdot$ Hiromi Okada $^{4}$. Nobuo Shinohara ${ }^{1}$

Published online: 7 July 2016

(C) Springer Science+Business Media New York 2016

\section{Erratum to: Surg Endosc}

\section{DOI 10.1007/s00464-015-4740-6}

There were errors in Table 2 as originally published. Regarding the margin status, negative: $n=19$ and positive: $n=6$ were correct. The correct version of Table 2 is reproduced here.
Table 2 Patients' outcomes

\begin{tabular}{ll}
\hline & $n=25$ \\
\hline $\begin{array}{l}\text { Operative time (min) } \\
\text { Blood loss (mL) }\end{array}$ & Median 208 (range 73-513) \\
Intraoperative complication & \\
Injury of vena cava & 1 \\
$\quad$ Injury of duodenum & 1 \\
Postoperative complication & \\
Depression & 1 (Grade 2) \\
Hypoglycemia & 1 (Grade 2) \\
Chylous leakage & 1 (Grade 1) \\
Postoperative hospital stay (days) & Median 8 (range 5-13) \\
Pathology & 12 \\
Paraganglioma & 7 \\
Ganglioneuroma & 6 \\
Schwannnoma & \\
Margin & 19 \\
Negative & 6 \\
Positive & \\
\hline
\end{tabular}

The online version of the original article can be found under doi:10.1007/s00464-015-4740-6.

Takashige Abe

takataka@rf6.so-net.ne.jp

1 Department of Urology, Hokkaido University Graduate School of Medicine, North-15, West-7, North Ward, Sapporo 060-8638, Japan

2 Department of Urology, Obihiro-Kosei General Hospital, Obihiro, Japan

3 Department of Urology, Hokkaido Cancer Center, Sapporo, Japan

4 Department of Surgical Pathology, Hokkaido University Hospital, Sapporo, Japan 